\title{
3D Motion Analysis of Hip, Knee and Ankle Joints of Children Aged Between 7-11 Years During Gait
}

\author{
Bülent Sabri Cığalı, Enis Uluçam, Cüneyt Bozer \\ Department of Anatomy, Faculty of Medicine, Trakya University, Edirne, Turkey
}

\begin{abstract}
Objective: The purpose of this study is to constitute a normative walking kinematic database and to investigate the differences between $7-11$ aged children and between the left and right sides of those age groups.
\end{abstract}

Materials and Methods: Fifty children between the 7 and 11 years old (10 from each age group) participated in this study. The measurements were made with Zebris@ CMS 70 P 3D motion analysis system. Flexion- extension, abduction-adduction angles of the hip joint, the flexion-extension of the knee and ankle joints and foot rotations for each age group for both sides were recorded.

Results: Even all the groups' gait patterns were similar with the literature, 9 years old group has lower knee flexion and higher ankle extensions $(p<0.05)$. Eight and 9 years old groups have higher maximum ankle extension values when compared with the other age groups ( $\mathrm{p}<0.05$ ).

Conclusion: Kinematic analysis results of 7 to 11 years old children suggests adult-like gait patterns especially for the hip and knee. These findings stress the importance of age-matched normative data for the kinematic gait analysis.

Key Words: Hip, knee, ankle, joint movement, gait kinematics

Received: 21.09.2010

Accepted: $21 \cdot 10.2010$

\section{Introduction}

Walking is described as a movement that is executed with the integration of neuromuscular and skeletal systems (1). Systematic study of human locomotion by measuring body movements, body mechanics, and the activity of the muscles is called gait analysis. It has been performed objectively with computer-assisted digital systems since 1980's. Today there are lots of equipments which are used in gait analysis. The most important need of the departments that use these equipments is the constitution of normal data to compare with the patients' data. In this study we aimed to evaluate flexion- extension, abduction- adduction angles of the hip joint, flexion- extension angles of knee and ankle joints and foot rotations by constituting a normal group and analyze their results to compare with those of handicapped children in future.

The availability of age matched normative gait data is an essential component of clinical gait analyses for diagnosing the abnormal gait. Gait analysis in children has been made since 1980's (1). From the beginning of 1990's researchers began to analyze the age-related differences in gait kinetics and kinematics. However, developmental studies on age matched gait analysis are limited in the literature. Researches about pediatric kinematics have reported adult like kinematic patterns by the ages of 5 and 7 years. Previous studies generally include comparison of the results with adult values (2-4).
On the other hand, these comparisons should be done between the groups depending on the age specific anthropometric data (4). Otherwise, because of the effect of joint kinematics, some statistical differences between equal groups may occur. Many of these results provide that a 7 year old child has similar gait with adults although there are some age maturity differences in gait kinematics (5). There are various factors of maturity of gait patterns, such as the muscle recruitment variability, immature strategies of equilibrium under 7 years old, immature sensory integration, developmental differences of body segments.

The purpose of this study is to constitute a normative database and to investigate the differences between different age groups and between the left and right sides of children in primary-school age groups.

\section{Materials and Methods}

Fifty Caucasian (10 from each age group) children attending to State School of Music participated in this study. Children were told that the purpose of the study was to provide data for therapy and follow up of their handicapped peers. The families of children were informed by the teachers. Parents of all children gave consent for participating in the measurements. Study protocol approved by Local Ethics Committee. The anthropometric characteristics of different age groups are given in Table 1. 
Before measurements, all children were examined by a physician for physical disorders and none of them was eliminated due to skeletal abnormalities. The students attended for measurements in the laboratory according to the program that was defined with their age groups and all measurements were made by the same crew, at the same time period of each day. The measurements were made by using Zebris ${ }^{\odot}$ CMS 70P 3D motion analysis system.

Four transmitters were placed on each side; one on the mid-thigh, one on the knee joint just between the lateral condyles of femur and tibia, the third one on the lateral malleolus and the last one on the fifth metatarsal head. Thus, the lower extremity was modelled as three rigid parts joined by articulations. Subjects with transmitters attached were walked for 5 meters on the runway. This procedure was repeated five times for each subject. Samples were recorded every 50 milliseconds. The clearest record was chosen for evaluation and reporting. Then, these records were checked against the errors in computer and graphs were drawn for flexion-extension, abduction-adduction angles of the hip joint; the flexion-extension of the knee and ankle joints and foot rotations for each age group for both sides. For statistical analysis the peak values recorded during these movements were used. Repeated measurements of ANOVA were used to identify significant differences among the age groups. For pairwise comparisons for both sides, Tukey's post hoc test was performed.

\section{Results}

The mean values of weight, height and the number of children for each group were given in Table 1. As expected, the height and weight values showed an increase in group of 11 years of age with respect to the group of 7 years of age. The groups represented the physical characteristics of their age group.

The peak values recorded during the movements of hip, knee and ankle were represented in Table 2, Table 3 and Table 4 , respectively. There were significant differences $(p<0.05)$ for maximum knee flexions and maximum internal foot rotations in the group of 9 years of age. Statistically significant difference $(p<0.05)$ was found in maximum ankle extension in the groups of 8 and 11-years of age when compared with the other age groups.

In the comparison of the right and left side parameters, there are significant differences between the maximum right hip abduction of the 10 year-old group (Table 2) and maximum right knee flexion of the 9 year-old group, maximum right knee extension of 10 year-old group (Table 3 ) and for the ankle movements maximum right flexion of the 11 yearold group, maximum right extension of 8,10 and 11 years old groups and finally maximum right foot internal rotation of 11 year-old group (Table 4). Comparing asymmetry in gait has been evaluated using some indexes for obtaining more reliable results (6). We use only one clear trial for evaluating the peak levels of angular movements of children. So this may cause some unexpected differences.

Mean normative flexion-extension, abduction-adduction angles of the hip joint, flexion-extension of the knee and ankle joints of both sides and foot rotations can be seen in each graphic (Figures 1, 2 and 3). Besides, the percentage of stance and swing phases can be seen in Figure 4.

Table 1. The anthropometric characteristics accross age groups

\begin{tabular}{|c|c|c|c|c|c|}
\hline & $\begin{array}{c}7 \text { years old } \\
(n=10)\end{array}$ & $\begin{array}{c}8 \text { years old } \\
(n=10)\end{array}$ & $\begin{array}{c}9 \text { years old } \\
(n=10)\end{array}$ & $\begin{array}{c}10 \text { years old } \\
(n=10)\end{array}$ & $\begin{array}{l}11 \text { years old } \\
(n=10)\end{array}$ \\
\hline & Mean \pm SD & Mean $\pm S D$ & Mean \pm SD & Mean \pm SD & Mean $\pm S D$ \\
\hline Weight, kg & $22.2 \pm 3.4$ & $26.7 \pm 3.6$ & $29.2 \pm 4.2$ & $31.5 \pm 5.2$ & $39.5 \pm 4.8$ \\
\hline Height, cm & $124.6 \pm 6.5$ & $127 \pm 5.2$ & $131.6 \pm 5.6$ & $136 \pm 5.1$ & $142.8 \pm 6.5$ \\
\hline BMI, kg/m² & $14.3 \pm 2.1$ & $16.1 \pm 2.4$ & $16.9 \pm 2.2$ & $16.8 \pm 2.3$ & $19.3 \pm 2.4$ \\
\hline
\end{tabular}

Table 2. Mean hip movements across age groups

\begin{tabular}{|c|c|c|c|c|c|c|c|c|c|c|}
\hline \multirow[t]{2}{*}{ Movement } & \multicolumn{2}{|c|}{7 years old } & \multicolumn{2}{|c|}{8 years old } & \multicolumn{2}{|c|}{9 years old } & \multicolumn{2}{|c|}{10 years old } & \multicolumn{2}{|c|}{11 years old } \\
\hline & Mean & SD & Mean & SD & Mean & SD & Mean & SD & Mean & SD \\
\hline Max. right hip flex. & 27.10 & 5.54 & 28.40 & 3.66 & 24.08 & 6.36 & 28.08 & 3.45 & 26.00 & 3.11 \\
\hline Max. left hip flex. & 27.70 & 5.21 & 26.53 & 7.22 & 23.21 & 8.58 & 29.23 & 4.57 & 26.50 & 4.53 \\
\hline Max. right hip ext. & -7.84 & 4.52 & -8.66 & 5.02 & -7.06 & 6.65 & -10.50 & 5.68 & -9.14 & 5.92 \\
\hline Max. left hip ext. & -7.74 & 6.76 & -9.20 & 4.21 & -6.90 & 3.57 & -8.03 & 3.37 & -7.49 & 3.80 \\
\hline Max. right hip abd. & $2.75^{\dagger}$ & 1.96 & 4.30 & 2.41 & 3.81 & 4.11 & $4.92^{\dagger}$ & 2.74 & 3.62 & 1.85 \\
\hline Max. left hip abd. & 6.33 & 5.54 & 3.56 & 1.72 & 1.51 & 4.44 & 2.87 & 2.48 & 2.58 & 3.31 \\
\hline Max. right hip add. & $-2.61^{\dagger}$ & 2.69 & $-1.57^{\dagger}$ & 3.00 & -2.51 & 2.10 & -1.47 & 0.74 & -1.66 & 2.82 \\
\hline Max. left hip add. & -0.30 & 2.10 & -3.30 & 2.32 & -3.47 & 5.24 & -2.96 & 2.57 & -2.19 & 2.22 \\
\hline
\end{tabular}


Table 3. Mean knee movements across age groups

\begin{tabular}{|lccccccccccc|}
\hline \multirow{2}{*}{ Movement } & \multicolumn{3}{c}{7 years old } & \multicolumn{3}{c}{$\mathbf{8}$ years old } & \multicolumn{2}{c}{ 9 years old } & \multicolumn{2}{c|}{ 10 years old } & \multicolumn{2}{c|}{11 years old } \\
\cline { 2 - 14 } & Mean & SD & Mean & SD & Mean & SD & Mean & SD & Mean & SD \\
\hline Max. right knee flex. & 47.92 & 11.73 & $51.30^{\dagger}$ & 8.51 & $39.98^{\star}$ & 21.76 & 44.72 & 10.07 & 52.80 & 14.24 \\
Max. left knee flex. & 41.38 & 4.24 & 35.82 & 12.10 & $33.56^{\star}$ & 12.87 & 45.66 & 10.46 & 55.56 & 3.11 \\
Max. right knee ext. & 2.98 & 6.31 & 0.05 & 1.18 & 4.98 & 2.65 & $3.64^{\dagger}$ & 5.35 & 1.87 & 5.44 \\
Max. left knee ext. & 3.14 & 2.05 & -1.76 & 3.73 & -4.57 & 7.67 & -7.06 & 6.76 & 2.43 & 7.00 \\
\hline
\end{tabular}

*: Significant differences $(p<0.05)$ in knee flexion values were found between the group of 9 years of age and the other age groups. Max: maximum, flex: flexion, ext: extension, ${ }^{t}$ : Significant differences between right and left sides $(p<0.05)$

Table 4. Mean ankle movements across age groups

\begin{tabular}{|c|c|c|c|c|c|c|c|c|c|c|}
\hline \multirow[t]{2}{*}{ Movement } & \multicolumn{2}{|c|}{7 years old } & \multicolumn{2}{|c|}{8 years old } & \multicolumn{2}{|c|}{9 years old } & \multicolumn{2}{|c|}{10 years old } & \multicolumn{2}{|c|}{11 years old } \\
\hline & Mean & SD & Mean & SD & Mean & SD & Mean & SD & Mean & SD \\
\hline Max. right ankle flex. & 6.85 & 21.53 & 3.58 & 6.34 & 6.04 & 1.91 & 6.92 & 2.97 & $7.90^{+}$ & 2.62 \\
\hline Max. left ankle flex. & 9.63 & 10.92 & 3.88 & 9.03 & 6.56 & 3.69 & 5.30 & 3.67 & 12.08 & 12.27 \\
\hline Max. right ankle ext. & -12.33 & 8.07 & $-24.94^{\star \dagger}$ & 7.84 & -8.22 & 9.53 & $-9.30^{+}$ & 3.66 & $-14.26^{\star+}$ & 9.20 \\
\hline Max. left ankle ext. & -10.18 & 4.92 & $-15.62^{\star}$ & 12.79 & -10.60 & 4.53 & -16.50 & 2.64 & $-21.85^{\star}$ & 6.03 \\
\hline Max. right foot external rot. & $11.00^{+}$ & 11.80 & 3.08 & 7.10 & -1.56 & 5.59 & 1.45 & 0.92 & 5.20 & 9.00 \\
\hline Max. left foot external rot. & 5.84 & 20.75 & 2.94 & 8.53 & 8.93 & 14.10 & 6.58 & 14.68 & 17.56 & 18.16 \\
\hline Max. right foot internal rot. & -18.56 & 11.80 & -5.64 & 7.07 & $-5.86^{*}$ & 1.76 & -12.26 & 3.27 & $-6.04^{\dagger}$ & 5.70 \\
\hline Max. left foot internal rot. & -15.02 & 27.02 & -1.88 & 11.73 & $-3.04^{\star}$ & 5.96 & -12.60 & 1.27 & -12.78 & 30.43 \\
\hline
\end{tabular}

\section{Discussion}

The purpose of this study was to determine if gait kinematics differ between various age groups of children and to obtain a normative database in order to use in the gait laboratories. Even we found some significant differences between some peak levels, the results demonstrated that gait patterns of each group seem similar.

The results obtained in this study were related to kinematic analysis of gait, namely the part which studies on the angular movement values. Temporal and spatial data can be obtained in this procedure. We evaluated stance and swing phases in percentage by analyzing these data in this study. According to these results the stance phase is tend to be shorter in young ages but the values did not differ from the classical value of stance phase which is $60 \%$ significantly (7-9). Again, the shortening of stance phase depending on age and tendency of increase in swing phase was consistent with the literature $(10,11)$. The kinematic data were given in Figures 1,2 and 3 . In these graphics 0 time value indicated the heel contact which was the start of the step and finish indicated the contact of heel to floor again. The curves of flexion-extension movements were near to those reported in the literature. In the knee joint there are two periods of flexion: the first period serves as shock absorber during loading response and the second period provides foot clearence during initial swing by showing a peak. Furthermore, there are two flexion curves in the ankle joint: the first occurs during the loading response and the second curve occurs during the stance phase. In the graphics of foot rotations, the positive side represents the external rotation and the negative side represents the internal rotation. In the relevant literature, the number of degrees of internal rotation is given about $4^{\circ}$ from heel contact throughout the stance phase and then shows an external rotation to a peak of 10 degrees in terminal swing. However, the foot rotation results obtained in this study were not clear as those reported in the literature. Inadequate number of children, immature development of musculoskeletal coordination might be the underlying reason for these results. Although some authors have considered that the gait maturity is completed at about 5 years of age, their findings were mostly from the analysis of sagittal plane movements (12).

The curves of hip flexion-extension movements were similar with the literature (13). But in this study the initiation values are lower between 5 and 10 degrees according to the literature. Any relevant report about the other age groups could not be found in the literature for comparison. In the coronal plane, movements of the hip joint, adduction has occurred in the stance phase and abduction has occurred in the swing phase of the gait cycle, as are in the literature. The movement angles between abduction and adduction of the hip joint were about 5 degrees and consistent with the literature $(11,13)$. Comparison of kinematic parameters for 3-13 years was made by Chester et al. But no comparison between left and right sides was made (13).

The results of this study are the mean values for 7-11 age groups and essential for the comparison with the results of pa- 


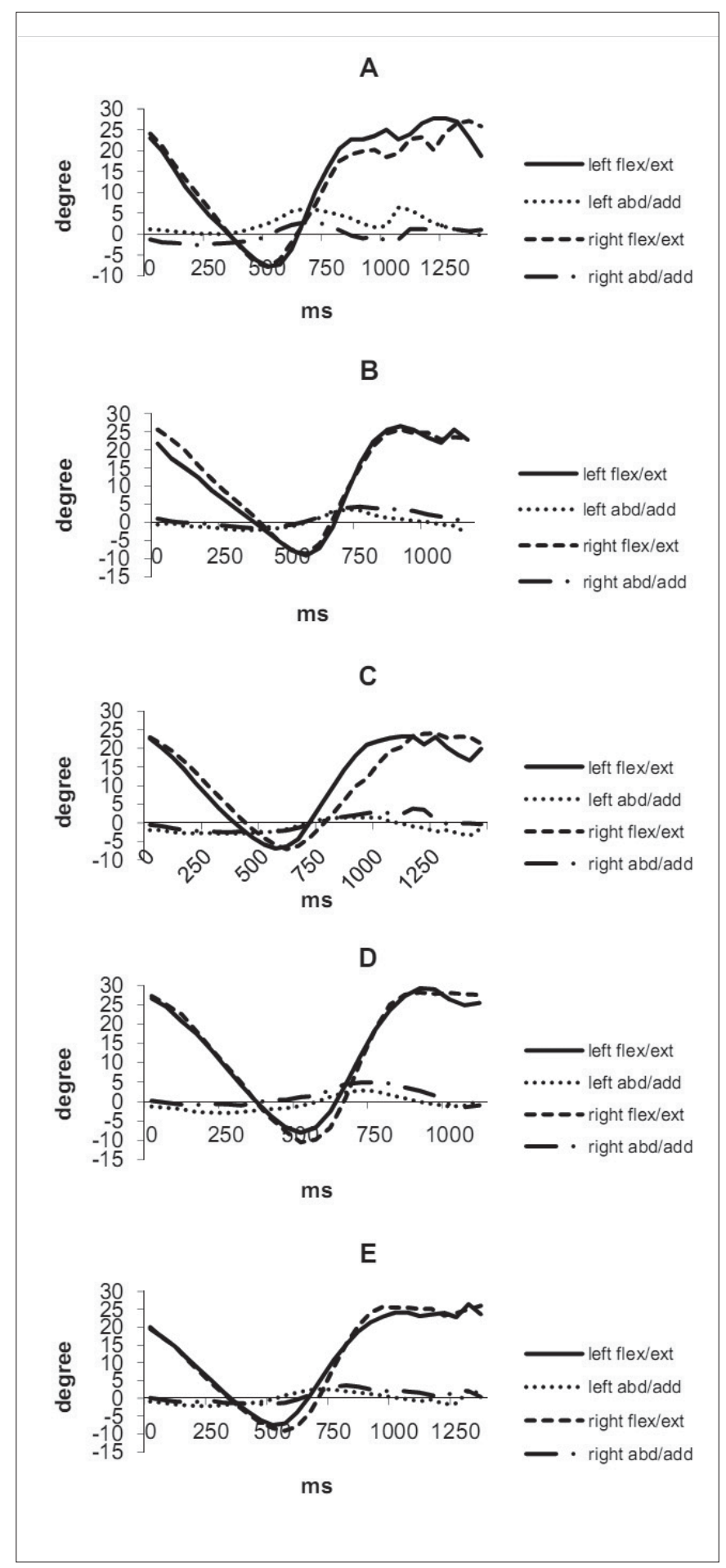

Figure 1. Hip movement graphics of all age groups. A: 7 years old, B: 8 years old, C: 9 years old, D: 10 years old, E: 11 years old

tients in these age groups and can serve as reference for the assessment of possible orthopedic disorders in children with similar ages (14). In comparison with the other tests' graphs, the foot rotation graphs were not clear enough. Even though this study was kinematic and did not include children under 5 years old, the difference between adults and children under five years old in ankle kinetics was also mentioned in the lit-
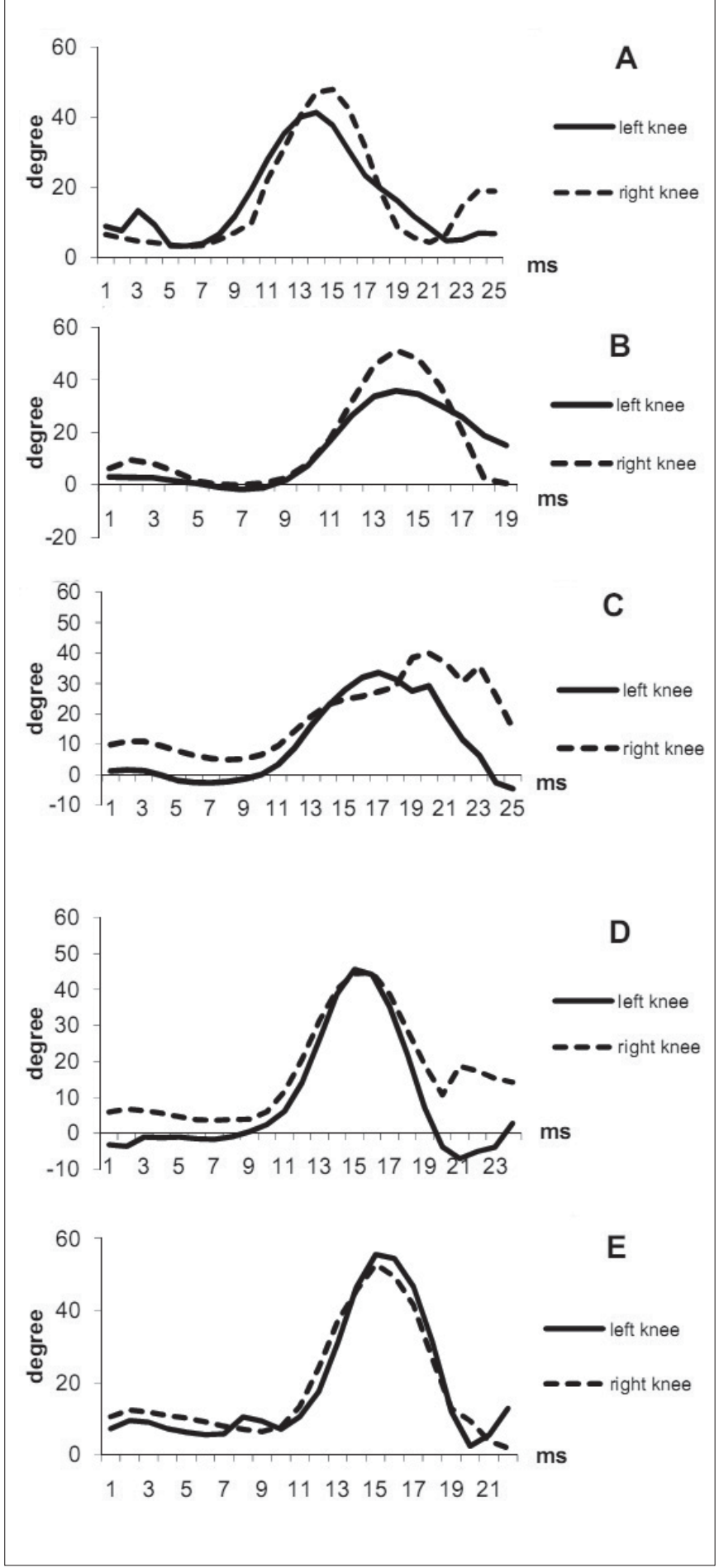

Figure 2. Knee movement graphics of all age groups. A: 7 years old, B: 8 years old, C: 9 years old, D: 10 years old, E: 11 years old

erature $(15,16)$. This supports some late maturation of ankle joint movements or moments.

\section{Limitations}

This study is a cross-sectional one and if a longitudinal study will be planned it would be more valuable.The mean values given in the figures are the mean of 10 subjects' 

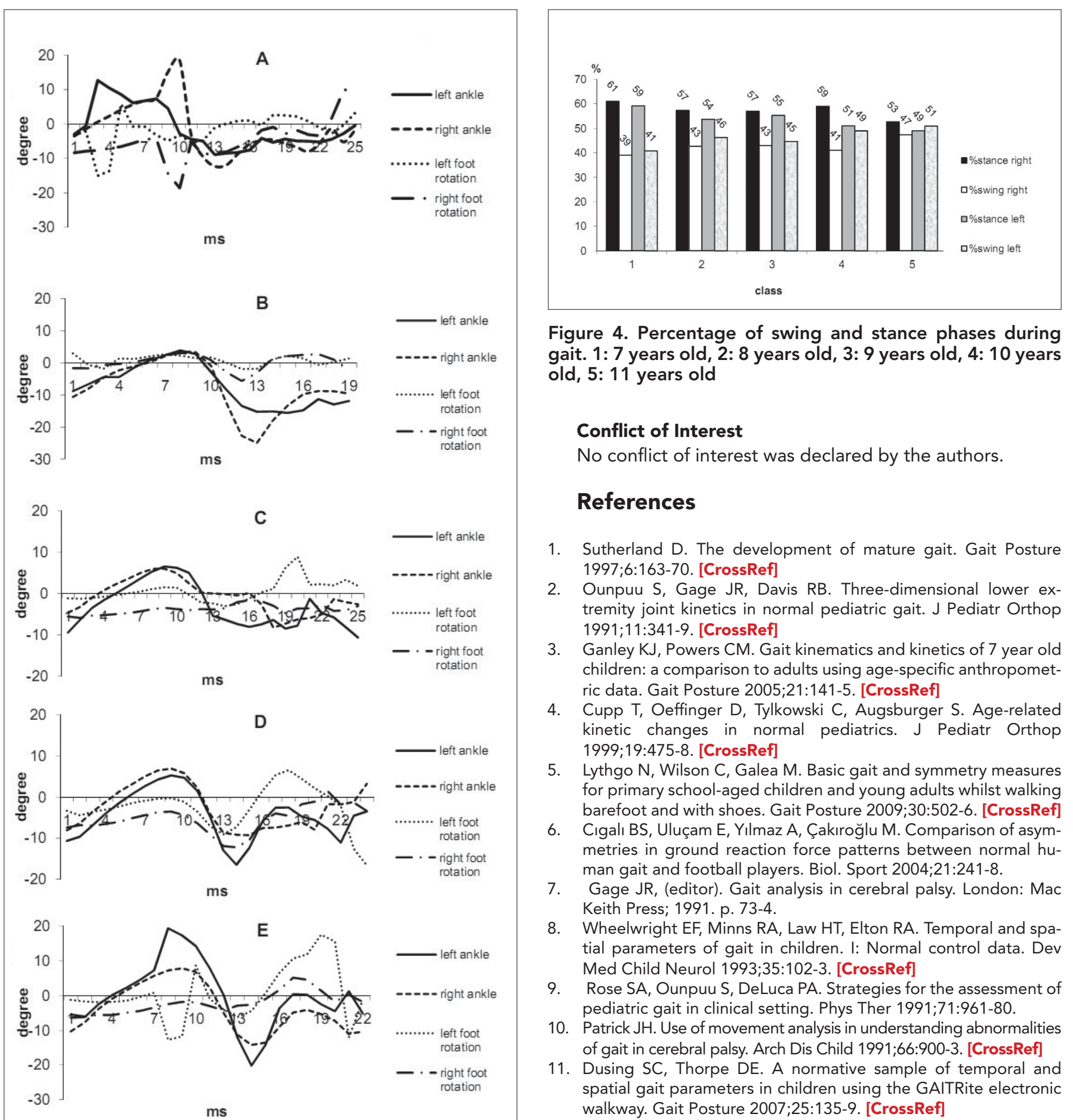

Figure 3. Ankle movement graphics of all age groups. A: 7 years old, B: 8 years old, C: 9 years old, D: 10 years old, E: 11 years old

clearest results. If the total 5 steps of each subject could be taken for evaluation the mean values would be more appropriate. More reliable results can be taken in larger study groups by measuring asymmetries in gait by using relevant formulas.

The tables according to sex would be more reliable if the subjects' number increased.
Figure 4. Percentage of swing and stance phases during gait. 1: 7 years old, 2: 8 years old, 3: 9 years old, 4: 10 years old, 5: 11 years old

\section{Conflict of Interest}

No conflict of interest was declared by the authors.

\section{References}

1. Sutherland D. The development of mature gait. Gait Posture 1997;6:163-70. [CrossRef]

2. Ounpuu S, Gage JR, Davis RB. Three-dimensional lower extremity joint kinetics in normal pediatric gait. J Pediatr Orthop 1991;11:341-9. [CrossRef]

3. Ganley KJ, Powers CM. Gait kinematics and kinetics of 7 year old children: a comparison to adults using age-specific anthropometric data. Gait Posture 2005;21:141-5. [CrossRef]

4. Cupp T, Oeffinger D, Tylkowski C, Augsburger S. Age-related kinetic changes in normal pediatrics. J Pediatr Orthop 1999;19:475-8. [CrossRef]

5. Lythgo N, Wilson C, Galea M. Basic gait and symmetry measures for primary school-aged children and young adults whilst walking barefoot and with shoes. Gait Posture 2009;30:502-6. [CrossRef]

6. Cıgalı BS, Uluçam E, Yılmaz A, Çakıroğlu M. Comparison of asymmetries in ground reaction force patterns between normal human gait and football players. Biol. Sport 2004;21:241-8.

7. Gage JR, (editor). Gait analysis in cerebral palsy. London: Mac Keith Press; 1991. p. 73-4.

8. Wheelwright EF, Minns RA, Law HT, Elton RA. Temporal and spatial parameters of gait in children. I: Normal control data. Dev Med Child Neurol 1993;35:102-3. [CrossRef]

9. Rose SA, Ounpuu S, DeLuca PA. Strategies for the assessment of pediatric gait in clinical setting. Phys Ther 1991;71:961-80.

10. Patrick JH. Use of movement analysis in understanding abnormalities of gait in cerebral palsy. Arch Dis Child 1991;66:900-3. [CrossRef]

11. Dusing SC, Thorpe DE. A normative sample of temporal and spatial gait parameters in children using the GAITRite electronic walkway. Gait Posture 2007;25:135-9. [CrossRef]

12. Chester VL, Tingley M, Biden EN. Comparison of two normative paediatric gait databases. Dyn Med 2007;6:8. [CrossRef]

13. Chester VL, Tingley M, Biden EN. A comparison of kinetic gait parameters for 3-13 year olds. Clin Biomech (Bristol, Avon) 2006;21:726-32. [CrossRef]

14. Baker R, McGinley JL, Schwartz MH, Beynon S, Rozumalski A, Graham HK, et al. The Gait Profile Score and Movement Analysis Profile. Gait Posture 2009;30:265-9. [CrossRef]

15. Lythgo N, Wilson C, Galea M. Basic gait and symmetry measures for primary school-aged children and young adults whilst walking barefoot and with shoes. Gait Posture 2009;30:502-6. [CrossRef]

16. Tingley $M$, Wilson $C$, Biden $E$, Knight WR. An index to quantify normality of gait in young children. Gait Posture 2002;16:149-58. [CrossRef] 